\title{
Mechanical Properties of the Every Second Matters for Mothers-Uterine Balloon Tamponade (ESM-UBT) Device: In Vitro Tests
}

\author{
Kamyar Mollazadeh-Moghaddam, PharmD ${ }^{1}$ Michelle Dundek, BE ${ }^{1}$ Anuj Bellare, $\mathrm{PhD}^{1}$ \\ Anderson Borovac-Pinheiro, MD ${ }^{1,2}$ Alice Won, MD ${ }^{1}$ Thomas F. Burke, MD ${ }^{1,3,4}$
}

${ }^{1}$ Division of Global Health Innovation, Department of Emergency Medicine, Massachusetts General Hospital, Boston, Massachusetts

2 Department of Obstetrics and Gynecology, School of Medical Sciences, University of Campinas, Campinas, São Paulo, Brazil

${ }^{3}$ Harvard Medical School, Boston, Massachusetts

${ }^{4}$ Harvard T. H. Chan School of Public Health, Boston, Massachusetts

\begin{abstract}
Address for correspondence Thomas F. Burke, MD, FACEP, FRSM, Division of Global Health Innovation, Department of Emergency Medicine, Massachusetts General Hospital, 125 Nashua Street, Suite 910, Boston, MA 02114 (e-mail: tfburke@mgh.harvard.edu).
\end{abstract}

Am J Perinatol Rep 2019;9:e376-e383.

\begin{abstract}
Keywords

- uncontrolled postpartum hemorrhage

- uterine balloon tamponade

- mechanical properties

- medical device

Objective Postpartum hemorrhage (PPH) is the most common cause of maternal mortality and morbidity worldwide, most of which occurs in resource-poor settings. Placement of a uterine balloon may be life-saving in uncontrolled PPH. The Every Second Matters for Mothers-Uterine Balloon Tamponade (ESM-UBT) device is an ultralow-cost uterine balloon designed for global access. The purpose of this study was to evaluate the mechanical properties of the ESM-UBT device.

Study design Intraluminal pressures, diameters, and burst volumes of condom uterine balloons and Foley catheter balloons of ESM-UBT devices were measured in open air and inside uterus models. Condom uterine balloons were tested with uterus model sizes of 100, 250, and $500 \mathrm{~mL}$. The condom-catheter O-ring attachment tensile strength was also evaluated. Results All 28 samples of ESM-UBT condom uterine balloons maintained their integrity for at least 3 hours when subjected to pressures of $200 \mathrm{~mm} \mathrm{Hg}$ or greater across each of the tested uterine volumes. No Foley catheter balloons burst after instillation of $30 \mathrm{~mL}$, O-rings withstood forces of $15.4 \pm 2.1 \mathrm{~N}$, and condom uterine balloons stretched to $35.8 \pm 2.1 \mathrm{~cm}$ without loss of integrity.

Conclusion The mechanical properties of the ESM-UBT device make it attractive for scale across resource-poor settings.
\end{abstract}

Uncontrolled postpartum hemorrhage (PPH) is a life-threatening emergency and the most common cause of maternal death and disability worldwide. Women in resource-poor settings are at greatest risk of PPH. ${ }^{1,2} \mathrm{PPH}$ and severe PPH are defined as blood loss of $\geq 500$ and $\geq 1000 \mathrm{~mL}$ within 24 hours after birth. $^{3}$ This amount of blood loss may lead to hemorrhagic shock acutely and, if a woman survives, anemia for long-term. ${ }^{4}$ Initial interventions for uncontrolled postpartum bleeding include uterine fundal massage, uterotonic medications, and tranexamic acid. If bleeding continues, further options include compressive measures such as uterine packing, bimanual uterine compression, uterine balloon tamponade (UBT), and external aortic compression; application of a nonpneumatic antishock garment; administration of blood components; arterial embolization; conservative surgical interventions; and hysterectomy, based on their availability. ${ }^{5,6}$ Placement of a UBT device may be a life-saving intervention in circumstances of atonic uterus, retained placenta, and placenta accreta. ${ }^{7}$ A UBT device is a balloon attached to a semirigid large bore catheter that acts as both received

May 17, 2019

accepted after revision

July 16, 2019
DOI https://doi.org/

10.1055/s-0039-1697653. ISSN 2157-6998.
Copyright $\odot 2019$ by Thieme Medical

Publishers, Inc., 333 Seventh Avenue, New York, NY 10001, USA. Tel: +1(212) 584-4662.
License terms

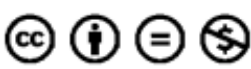


an introducer and as a channel to rapidly inflate the balloon once it is placed into the uterine cavity. ${ }^{7-10}$

Prior to the advent of balloon tamponade devices specific for the uterus, multiple balloon devices designed for use in the esophagus and/or stomach were reported successful when deployed for PPH management. ${ }^{8,11}$ More recently, balloon tamponade devices have been specifically designed for intrauterine application, such as the BT-Cath, the ebb Complete Tamponade System (ebb), the Rusch UBT, and the Bakri postpartum balloon catheter (Bakri) among others. ${ }^{12-18}$ While reports on patient outcomes associated with commercial UBT devices are encouraging, their high cost (up to $\$ 400$ USD) is a barrier to implementation across resource-poor settings. ${ }^{13}$

An improvised condom-catheter UBT is an alternative to a commercial UBT device. In improvised UBT devices, a condom is secured near the tip of a Foley catheter and inflated with water or saline via either gravity or a syringe. These devices require assembly; however, their low cost of materials makes them attractive options for resource-poor settings. ${ }^{19-23}$ Reported rates (75-94\%) of hemorrhage arrest among women that received commercial or condom-catheter UBTs have been encouraging. $7,13,24,25$

While condom-catheter UBT devices can be improvised with available materials, it is often difficult to find what is needed in a timely fashion during a PPH emergency. ${ }^{26}$ Component specifications affect the efficacy and ease of use of assembled condom-catheter UBT devices. For example, if a device is inflated using a 10cc syringe, it will take at least 50 injections to instill $500 \mathrm{cc}$. If there is any leak on instillation (invariable with improvised UBTs), adequate fill of a condom uterine balloon may require as many as 100 injections. The "Every Second Matters for Mothers-Uterine Balloon Tamponade" (ESM-UBT) device is a condom-catheter balloon tamponade device designed in 2010 by the Massachusetts General Hospital Division of Global Health Innovation (formerly the Division of Global Health and Human Rights) in the Department of Emergency Medicine to optimize safety, efficacy, and ease of use (-Fig. 1A). ESM-UBT devices are packaged in kits comprised of seven components (-Fig. 1B) and an instruction card (-Fig. 1C):

1. Foley catheter (Silicon/Retention catheters/24 French 5cc balloon/Sterile)

2. Condoms (Latex/Lubricated surface)

3. Luer lock valve for injection site (One-way valve: Luer lock inlet fits the syringe/Sterile)

4. O-rings (Elastic/5/8" ID)

5. Povidone-iodine prep pads

6. Catheter holder

7. Syringe ( $60 \mathrm{~mL} /$ Sterile)

ESM-UBT devices are being used in over 20 countries worldwide. $^{21,27-29}$ To-date, over 1,000 ESM-UBT devices have been placed in women with uncontrolled PPH in Kenya alone with survival rates of $95 \%$ overall. If placed prior to advanced shock, survival rates approach $100 \%{ }^{26,28}$

Although several studies have demonstrated the safety and clinical efficacy of ESM-UBT devices in individual cases, the mechanical properties of ESM-UBT devices are not well understood. The aim of this study was to provide a comprehensive evaluation of the mechanical properties of ESM-UBT devices.

\section{Methods}

ESM-UBT Kit Components and Assembly of the Device To assemble an ESM-UBT device, a condom (latex, lubricated, LifeStyles, NJ) is rolled out in its entirety and placed over the tip of a Foley catheter (silicone, retention catheter, 24 French $5 \mathrm{cc}$ balloon, sterile, Dover, MN) to cover the un-inflated Foley catheter balloon. The condom is secured $1 \mathrm{~cm}$ proximal to the uninflated Foley catheter balloon (-Fig. 1D) using an O-ring (Kraton polymer, 5/8" ID, Sheathes, CA). The O-ring is twisttied four times to establish a secure condom-catheter connection (-Fig. 1E). A Luer lock (DirectMed, NY) is placed into the proximal end of the drainage lumen of the Foley catheter with the female connector of the Luer lock exposed. A $60 \mathrm{~mL}$ syringe is attached to the Luer lock and fills the condom uterine balloon. An antiseptic PVP Iodine (Povidone Iodine $10 \%$ prep pad, Dynarex, NY) pad is used to wipe the surface of the assembled device. The complete ESM-UBT device assembly is illustrated in - Fig. 1F.

\section{Evaluation of the ESM-UBT Device Integrity}

\section{Evaluation of the Foley Catheter Balloon}

Diameters of Foley catheter balloons after inflation, burst volumes, and intraluminal pressures (ILP) were evaluated using a pressure vacuum meter (DigiMano 1000, Netech Corporation, Farmingdale, NY) and dial caliper (Mitutoyo America Corporation, Series 505, IL). Foley catheter balloons were filled to $90 \mathrm{~mL}$ of normal saline or until they burst. Diameters and ILPs were recorded after every $5 \mathrm{~mL}$ of normal saline instillation.

\section{Evaluation of the O-Ring Secured Attachment of the Condom Uterine Balloon to the Foley Catheter}

Tensile tests were performed to assess the strength of the 0 ring secured attachment of the condom uterine balloon to the Foley catheter. Assembled ESM-UBT devices were subjected to tensile stresses using a PARAM XLW (EC) Auto Tensile Tester. Tensile loads were increased at a crosshead speed of $100 \mathrm{~mm} \mathrm{~min}^{-1}$ until detachment. Maximum tolerated loads and elongations were recorded.

\section{Evaluation of the Condom Uterine Balloon in Open Air}

Condom uterine balloons' pressures after inflation, diameters, and burst volumes were evaluated. Condom uterine balloon ILPs were measured using the pressure vacuum meter. After the pressure meter was connected to ESM-UBT devices with connection tubing and two stopcocks ( - Fig. 2A), Foley catheter balloons were inflated with $15 \mathrm{~mL}$ of normal saline and left inflated throughout the experiment. One thousand two-hundred $\mathrm{mL}$ of normal saline was injected into the condom uterine balloon in $50 \mathrm{~mL}$ increments. At each step, the ILPs of the condom uterine balloons were measured and the maximum diameters recorded using the dial caliper. Once $1200 \mathrm{~mL}$ was 


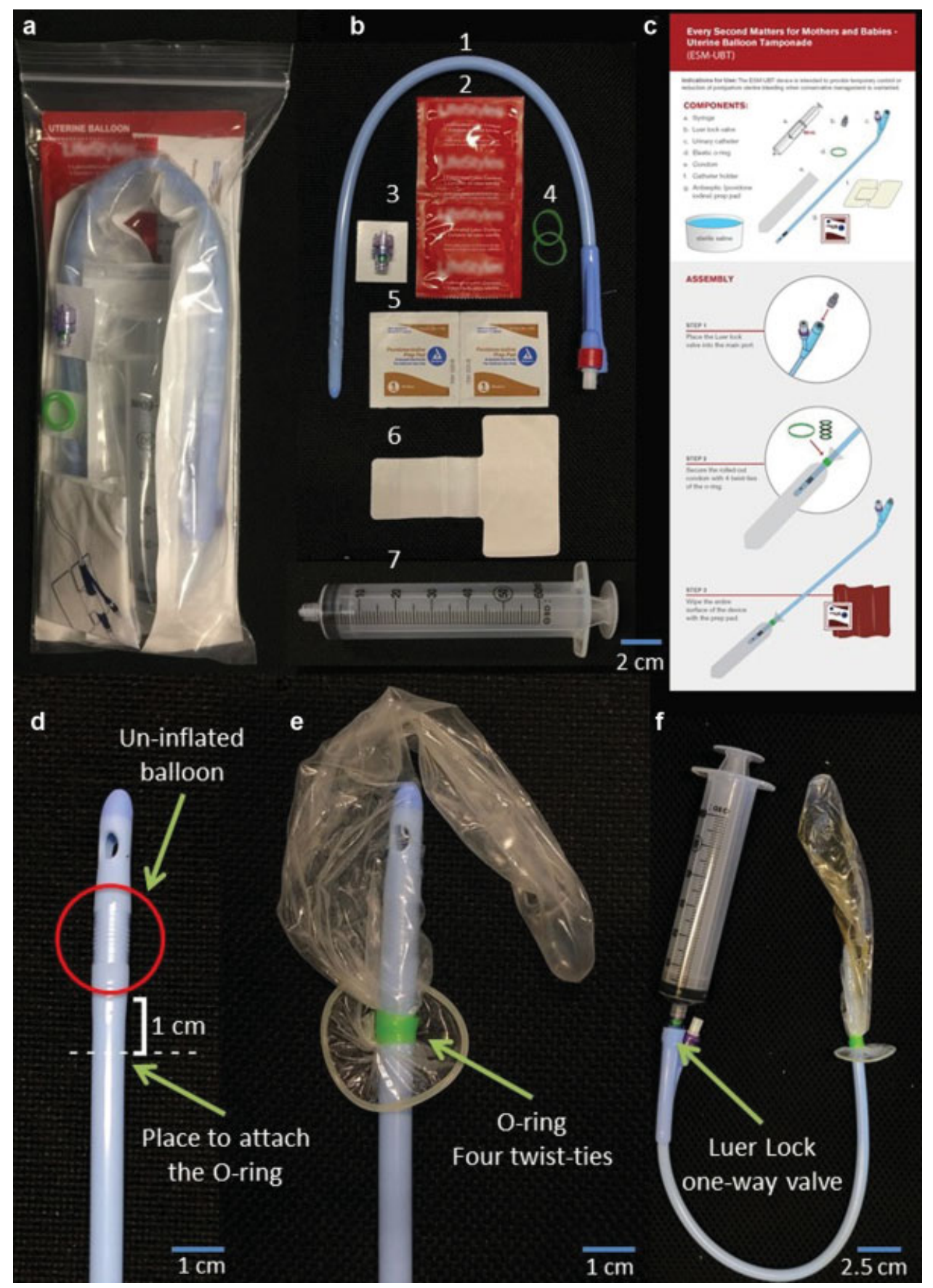

Fig. 1 Every Second Matters for Mothers-Uterine Balloon Tamponade (ESM-UBT) kit and device assembly: (A) Official ESM-UBT kit; (B) Seven components of ESM-UBT kit: 1/ Foley catheter, 2/ Condom, 3/ Check valve, 4/ O-rings, 5/ Povidone-iodine prep pads, 6/ Catheter Holder, and 7/ Syringe; (C) Front side of the instruction card; (D) Condom uterine balloon is attached $1 \mathrm{~cm}$ proximal to the Foley catheter balloon by an $\mathrm{O}$-ring; (E) O-ring is twist-tied four times; (F) Complete assembly of an ESM-UBT device with Luer lock and syringe.

instilled no further ILP or pressure measurements were performed. ESM-UBT condom uterine balloons were filled to $5,000 \mathrm{~mL}$ or until they burst.

\section{Evaluation of the Condom Uterine Balloon in Simulated Situations}

Uterus models were engineered to mimic shapes of uteri. ${ }^{30-33}$ Three uterus models were fabricated out of aluminum with cavity volumes of 100,250 , and $500 \mathrm{~mL}$ and circular openings created to resemble cervical orifices. ESM-UBT condom uterine balloons were placed in the rigid uterus models to evaluate the integrity of the device when subjected to high ILPs. The ILPs generated in these experiments were designed to be intentionally higher than ILP previously measured in UBT devices placed in women to stress the ESM-UBT device in a worst-case scenario. The average postpartum human cervical lip diameter is $1.81 \mathrm{~cm}$ (range from 0.50 to $4.21 \mathrm{~cm}$ ); therefore, simulated cervical diameter openings in the uterus models were set at $1.5,2$, and $2.5 \mathrm{~cm}$, respectively ${ }^{34}$ (-Fig. 2B and C). Uterus models were positioned with the openings downward to simulate a worst-case scenario vulnerable to expulsion of the ESM-UBT device. Condom uterine balloons were placed 


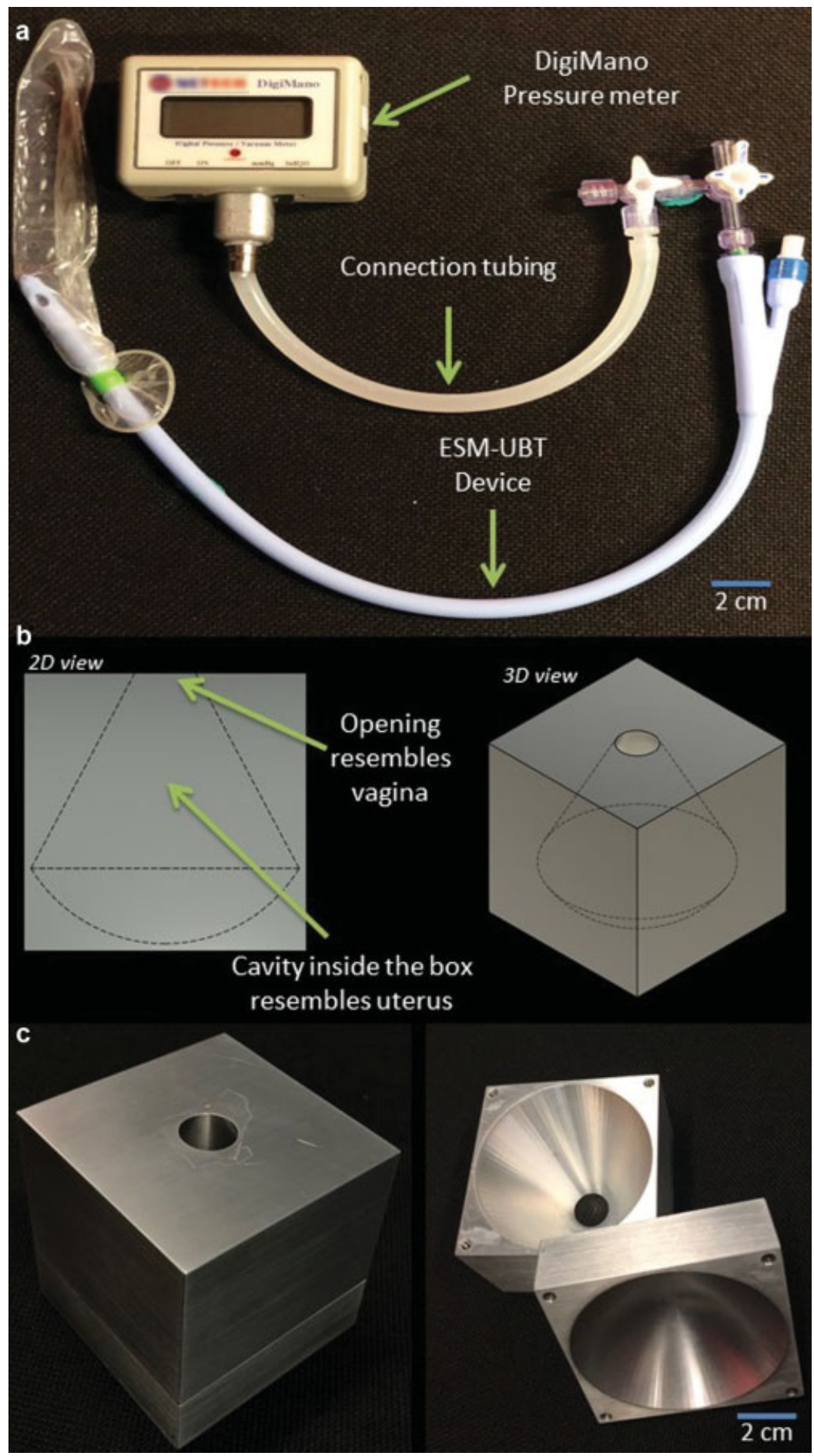

Fig. 2 Pressure evaluation for the ESM-UBT device: (A) Intraluminal pressure measurement system; (B) Uterus model design; (C) $250 \mathrm{~mL}$ aluminum uterus model. ESM-UBT, Every Second Matters for Mothers-Uterine Balloon Tamponade.

inside uterus models after assembly of the pressure meter system. Foley catheter balloons were inflated with $15 \mathrm{~mL}$ of normal saline and maximum volumes of normal saline were instilled into the condom uterine balloons. Maximum volumes were defined as the volumes above which the condom uterine balloons spilled from the uterus model's simulated cervical opening. ILPs of condom uterine balloons were recorded every hour for 4 hours. ESM-UBT device integrities were recorded throughout the experiments.

\section{Statistical Analysis}

The following formula was used to calculate sample size to gain $90 \%$ reliability and $95 \%$ confidence:

Sample size $=\operatorname{Ln}(1-$ confidence $) /$ Ln (reliability)

A sample size of 28 was used for every experiment with a unique variable (e.g., each uterine size). Results were represented as means \pm standard deviations. Error bars represent the standard error of mean. 

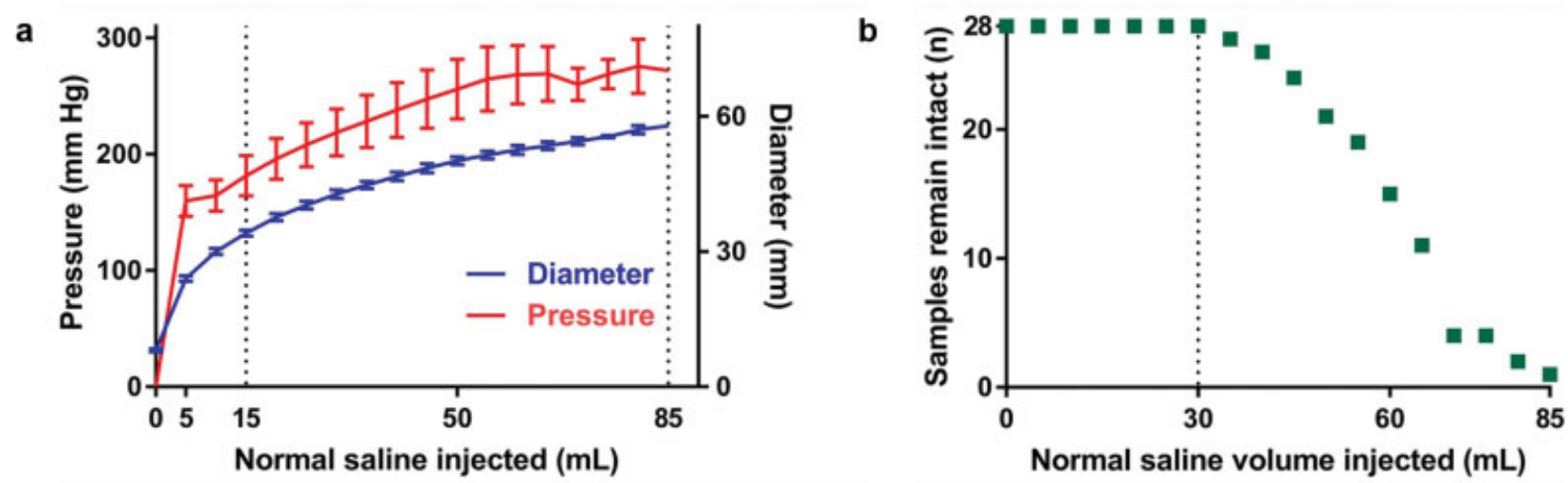

Fig. 3 ESM-UBT device Foley catheter balloon characteristics: (A) Intraluminal pressures and diameters of Foley catheter balloons; (B) Foley catheter balloons burst volumes. ESM-UBT, Every Second Matters for Mothers-Uterine Balloon Tamponade. "Error bars represent standard deviation.

\section{Results}

\section{Evaluation of ESM-UBT Foley Catheter Balloons} Initial diameters of Foley catheter balloons were $8.1 \pm 0.3 \mathrm{~mm}$. After $5 \mathrm{~mL}$ instillation of normal saline, pressures and diameters increased sharply to $159.9 \pm 13.4 \mathrm{~mm}$ $\mathrm{Hg}$ and $24.0 \pm 0.6 \mathrm{~mm}$, respectively. Foley balloon diameters increased to $34.1 \pm 0.7 \mathrm{~mm}$ after $15 \mathrm{~mL}$ of saline was instilled (-Fig. 3A). Foley catheter balloons gradually increased in both pressure and diameter with further instillation of normal saline. None of the 28 tested Foley catheter balloons burst with volumes of $30 \mathrm{~mL}$ of normal saline ( - Fig. 3B). The lowest burst volume was $35 \mathrm{~mL}$ and the maximum $90 \mathrm{~mL}$.

\section{Evaluation of the O-Ring Secured Condom Uterine Balloon Attachment to the Foley Catheter}

The maximum elongation and force at the point of failure of the condom-catheter connections were $35.8 \pm 2.1 \mathrm{~cm}$ and $15.1 \pm 2.1 \mathrm{~N}$, respectively ( - Fig. $\mathbf{4 A}$ and $\mathbf{B}$ ).

\section{Evaluation of ESM-UBT Condom Uterine Balloons in Open Air}

Pressures within condom uterine balloons in open air increased during instillation of the first $300 \mathrm{~mL}$ of normal saline and reached a maximum pressure of $12.4 \pm 1.4 \mathrm{~mm} \mathrm{Hg}$ (- Fig. 5A). Pressures remained stable (fluctuations $<1.5 \mathrm{~mm} \mathrm{Hg}$ ) with further instillation of normal saline up to $1200 \mathrm{~mL}$. Diameters of condom uterine balloons rapidly increased to $40.8 \pm 2.6 \mathrm{~mm}$ with instillation of an initial $50 \mathrm{~mL}$ of saline. With the further addition of normal saline, condom uterine balloons expanded at a more modest rate in a linear fashion. Maximum recorded diameters were $126.6 \pm 5.7 \mathrm{~mm}$ at $1200 \mathrm{~mL}$ volume of normal saline. None of the condom uterine balloons burst with $5000 \mathrm{~mL}$ of saline (-Fig. 5B).

\section{Evaluation of ESM-UBT Condom Uterine Balloons in Simulated Situations}

The volumes of normal saline tolerated by ESM-UBT devices prior to expulsion were 20 to $30 \mathrm{~mL}$ less than the volumes of the uterine cavities ( - Table 1). ILP of $363.6 \pm 74.7$, $399.9 \pm 78.1$, and $436.5 \pm 87.0 \mathrm{~mm} \mathrm{Hg}$ were observed at maximum (threshold) filling volumes inside the 100, 250, and 500mL uterus models, respectively ( - Table 1 and - Fig. 5C). After inflation, condom uterine balloons gradually pushed out through the openings. This phenomenon led to a gradual decrease in the ILP. Pressures decreased by 21.1, 22.9, and $21.3 \%$ in the first hour; 8.6, 9.4, and $11.5 \%$ in the second hour; and $9.7,7.1$, and $7.7 \%$ in the third hour in the 100,250 , and $500 \mathrm{~mL}$ uterus models, respectively. Pressures decreased at approximately the same rate in all three-uterus models (-Fig. 5C). Throughout the 3-hour experiment ESM-UBT devices experienced no leakage and they maintained full a

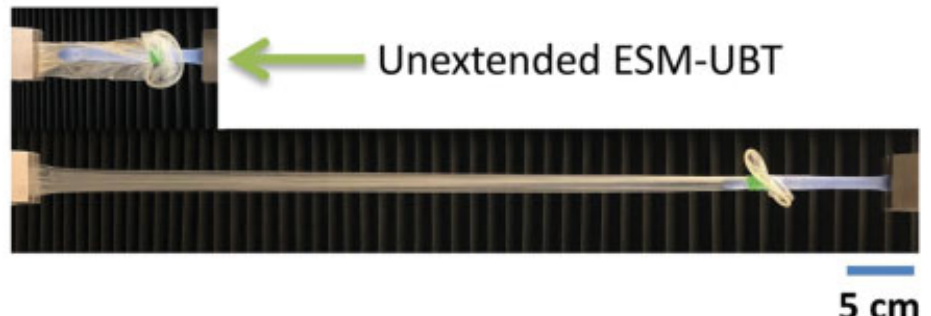

b

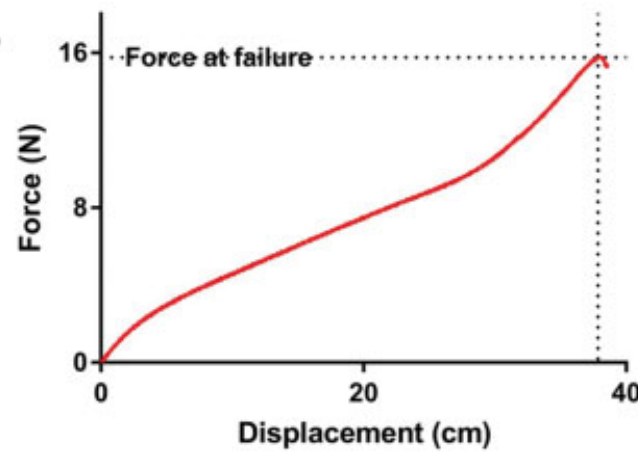

Fig. 4 O-ring secured attachment of the condom uterine balloon to the Foley catheters: (A) An ESM-UBT device sample during tensile extension; (B) Force-displacement curve. ESM-UBT, Every Second Matters for Mothers-Uterine Balloon Tamponade. 
a

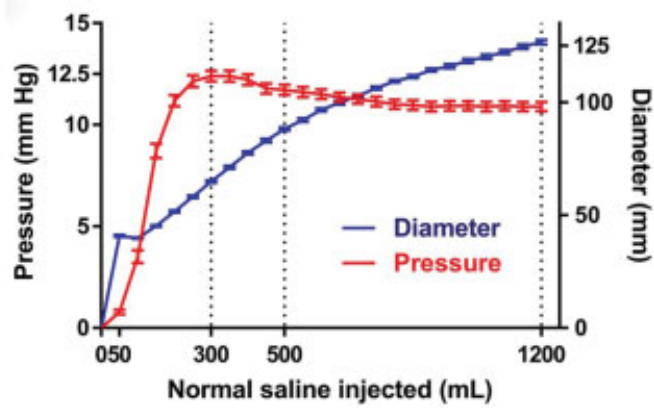

b

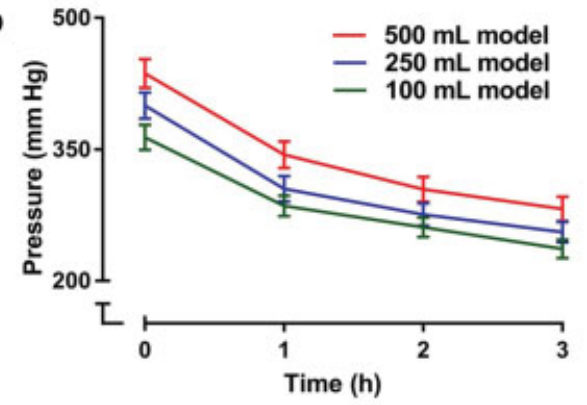

C

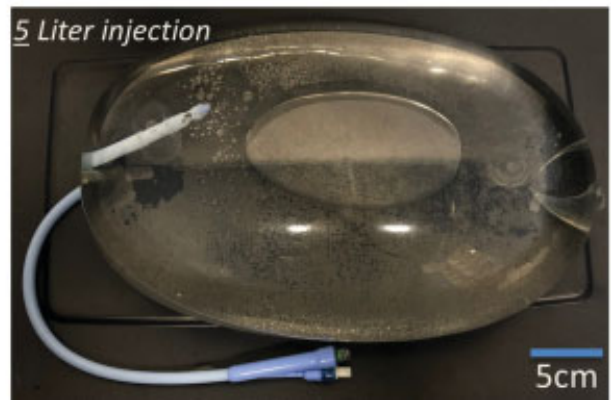

Fig. 5 ESM-UBT device condom uterine balloon characteristics: (A) Intraluminal pressures and diameters of condom uterine balloons in open air; (B) ESM-UBT device burst volume of $>5000 \mathrm{~mL}$; (C) Intraluminal pressures of condom uterine balloons in uterus models. ESM-UBT, Every Second Matters for Mothers-Uterine Balloon Tamponade. "Error bars represent standard error of mean.

integrity of their components. No ruptures were found in any ESM-UBT devices after deflation, removal, and inspection.

\section{Discussion}

Uncontrolled PPH is a significant cause of maternal death and disability worldwide. ${ }^{35,36}$ However, in resource-limited settings, commercial UBT devices are often not affordable. Reliance on skilled birth attendants to improvise UBT devices is fraught with suboptimal equipment, delays in device assembly, and poor uptake by providers across health systems. ${ }^{21,27-29}$ The ESM-UBT device was designed to overcome each of the challenges posed by commercial and improvised UBT devices. This study demonstrates that ESM-UBT devices maintain their pressures and integrity over the course of a series of experiments designed to stress and evaluate the ESM-UBT system.

When a woman is hemorrhaging from an atonic uterus, an ESM-UBT device is rapidly assembled and the distal end guided through the cervix and into the uterus either by a blind digital approach or via placement using a speculum and instruments. Although there is no evidence to support the practice, experi-

Table 1 Saline amounts that cause ESM-UBT device expulsion from uterus models

\begin{tabular}{|l|l|}
\hline $\begin{array}{l}\text { Uterus model } \\
\text { volume }(\mathrm{mL})\end{array}$ & $\begin{array}{l}\text { Volume of normal } \\
\text { saline injected }(\mathrm{mL})\end{array}$ \\
\hline 100 & $77.1 \pm 2.8$ \\
\hline 250 & $224.4 \pm 3.4$ \\
\hline 500 & $475.7 \pm 3.4$ \\
\hline
\end{tabular}

Abbreviation: ESM-UBT, Every Second Matters for Mothers-Uterine Balloon Tamponade.

Data presented as mean \pm standard deviation. enced $\mathrm{OB} / G Y N$ s frequently describe that installation of $15 \mathrm{~mL}$ fluid into the Foley catheter balloon immediately after placement of an ESM-UBT device helps seat the uterine balloon in the posterior uterus and decreases the likelihood of unwanted expulsion. In our laboratory simulations, Foley catheter balloons expanded $(34.1 \pm 0.7 \mathrm{~mm}$ ) beyond the average postpartum cervical orifice $(6.6 \pm 3.6 \mathrm{~mm})$ opening size after instillation of $15 \mathrm{~mL}$ of saline (-Fig. 3A). These findings support clinical reports that Foley catheter balloons decrease the likelihood of inadvertent expulsion. Additionally, while a common past practice has been to use only an inflated Foley catheter balloon in attempts to arrest postpartum atonic uterine hemorrhage, our study demonstrates that although Foley catheter balloons are reliably able to expand to $30 \mathrm{cc}$, they may burst at greater volumes and consequently are not able to provide a desired tamponade effect. ${ }^{37}$

Improvised UBTs are most commonly created by tying a condom to the distal end of a Foley catheter with twine or suture material. Both techniques are subject to considerable user variability and in the authors' experience condoms frequently slip off their Foley catheters when tied. To address this, ESM-UBT devices were designed with a standard method of securing condom uterine balloons to Foley catheters using four twists of a unique $\mathrm{O}$-ring. In tensile tests, the force required for failure $(15.4+2.1 \mathrm{~N})$ of the O-ring connection was considerably greater than what would occur in clinical circumstances, thereby demonstrating the O-ring's critical role in the overall integrity of an ESM-UBT device.

Although condoms are used worldwide to address uterine hemorrhage it is unknown whether condoms can completely conform to uterine cavities of varying size and shapes and withstand pressures necessary to maintain hemostasis. The pressure exerted by water-filled condoms on the uterine walls 
and their burst volumes are also unknown. In our experiments, $500 \mathrm{~mL}$ of normal saline expanded a condom uterine balloon's diameter to $88.1 \pm 3.8 \mathrm{~mm}$ and entirely filled the simulated post-delivery uterine cavities (- Fig. 5A). ${ }^{30,31}$

Skilled birth attendants are trained to instill saline into a UBT until bleeding ceases. ${ }^{7,8,38}$ The ESM-UBT device's condom uterine balloon diameter increases linearly with increasing amounts of saline and therefore allows for a smooth escalation of pressures against the endometrium surface ( $\mathbf{- F i g . 5 A}$ ). Open air tests of ESM-UBT devices demonstrated that with 200 and $500 \mathrm{~mL}$ of saline, condom uterine balloons achieved and maintained pressures ( $>10 \mathrm{~mm} \mathrm{Hg}$ at $200 \mathrm{~mL}$ ) comparable to premium commercial devices. ${ }^{8}$ Furthermore, while many commercial UBT devices are limited in size between 500 and $1,000 \mathrm{~mL}$, in the authors' experience, some women require uterine balloon volumes as much as $1,250 \mathrm{~mL}$ to arrest their hemorrhage after delivery of multiple newborns. None of the ESM-UBT device condom uterine balloons burst with volumes $\leq 5,000 \mathrm{~mL}$ of saline.

To assess whether ESM-UBT condom uterine balloons maintain their integrity during clinical use, anatomically correct aluminum uterus models were engineered to simulate real-life uterus dimensions. The rigid nature of the aluminum uterus models forced the condom uterine balloons into a worst-case scenario where the ILPs were greater than what would occur in an actual uterus. The finding that there were no losses of structural integrity in any of the tested devices supports the reliability of the ESM-UBT device for use in the clinical setting of PPH. $9,39,40$

While the models and open-air experiments in this study strongly suggest that ESM-UBT devices are durable enough to withstand pressures beyond those expected during clinical use, ILPs of ESM-UBT devices in actual uteri were not measured. Further studies are needed to better understand in vivo ILPs. Our study did not attempt to shed further light on the various theories on how UBTs work; therefore, further investigation is required to more clearly identify the role of pressure and other potential mechanisms of action of UBT devices.

\section{Conclusion}

The unique mechanical properties of the ESM-UBT device make it attractive for scale across resource-poor settings.

\section{Conflict of Interest}

None declared.

\section{Acknowledgments}

The authors thank Hogan Lovells, LLC for their tireless probono support, Ms. Nneoma Okonkwo for her contributions in executing the experiments, and the Ujenzi Charitable Trust for an unrestricted grant.

\section{References}

1 Kassebaum NJ, Bertozzi-Villa A, Coggeshall MS, et al. Global, regional, and national levels and causes of maternal mortality during 1990-2013: a systematic analysis for the Global Burden of Disease Study 2013. Lancet 2014;384(9947):980-1004
2 World Health Organization. World Health Statistics 2018 - Monitoring Health for the SGDs (Sustained Development Goals). Geneva, Switzerland: World Health Organization; 2018:100

3 World Health Organization. WHO Recommendations for the Prevention and Treatment of Postpartum Haemorrhage: Evidence Base. WHO Guidelines Approved by the Guidelines Review Committee. Geneva, Switzerland: WHO Library; 2012:48

4 Su CW. Postpartum hemorrhage. Prim Care 2012;39(01):167-187

5 Tunçalp O, Souza JP, Gülmezoglu M; World Health Organization. New WHO recommendations on prevention and treatment of postpartum hemorrhage. Int J Gynaecol Obstet 2013;123(03): 254-256

6 Shakur H, Roberts I, Fawole B, et al; WOMAN Trial Collaborators. Effect of early tranexamic acid administration on mortality, hysterectomy, and other morbidities in women with post-partum haemorrhage (WOMAN): an international, randomised, double-blind, placebo-controlled trial. Lancet 2017;389(10084):2105-2116

7 Georgiou C. Balloon tamponade in the management of postpartum haemorrhage: a review. BJOG 2009;116(06):748-757

8 Antony KM, Racusin DA, Belfort MA, Dildy GA III. Under pressure: intraluminal filling pressures of postpartum hemorrhage tamponade balloons. AJP Rep 2017;7(02):e86-e92

9 Georgiou C. Intraluminal pressure readings during the establishment of a positive 'tamponade test' in the management of postpartum haemorrhage. BJOG 2010;117(03):295-303

10 Keski-Nisula L, Heiskanen P, Heinonen S. Extra-membranous pregnancy, prolonged ruptured membranes and circumvallate placenta. Acta Obstet Gynecol Scand 2011;90(10):1170-1171

11 Seror J, Allouche C, Elhaik S. Use of Sengstaken-Blakemore tube in massive postpartum hemorrhage: a series of 17 cases. Acta Obstet Gynecol Scand 2005;84(07):660-664

12 Bakri YN, Amri A, Abdul Jabbar F. Tamponade-balloon for obstetrical bleeding. Int J Gynaecol Obstet 2001;74(02):139-142

13 Theron GB. Management of postpartum hemorrhage with freeflow pressure controlled uterine balloon. Int J Gynaecol Obstet 2018;142(03):371-373

14 Dildy GA, Belfort MA, Adair CD, et al; ebb Surveillance Study Team. Initial experience with a dual-balloon catheter for the management of postpartum hemorrhage. Am J Obstet Gynecol 2014;210(02):136.e1-136.e6

15 Lau MSK, Tee JCS. Use of a large Rusch hydrostatic catheter balloon to control postpartum haemorrhage resulting from a low placental implantation. Singapore Med J 2009;50(09): e321-e323

16 Uygur D, Altun Ensari T, Ozgu-Erdinc AS, Dede H, Erkaya S, Danisman AN. Successful use of BT-Cath $\left({ }^{\circledR}\right)$ balloon tamponade in the management of postpartum haemorrhage due to placenta previa. Eur J Obstet Gynecol Reprod Biol 2014;181:223-228

17 McQuivey RW, Block JE, Massaro RA. ebb ${ }^{\circledR}$ Complete Tamponade System: effective hemostasis for postpartum hemorrhage. Med Devices (Auckl) 2018;11:57-63

18 Wright CE, Chauhan SP, Abuhamad AZ. Bakri balloon in the management of postpartum hemorrhage: a review. Am J Perinatol 2014;31(11):957-964

19 Rathore AM, Gupta S, Manaktala U, Gupta S, Dubey C, Khan M. Uterine tamponade using condom catheter balloon in the management of non-traumatic postpartum hemorrhage. J Obstet Gynaecol Res 2012;38(09):1162-1167

20 Rani PR, Begum J. Recent advances in the management of major postpartum haemorrhage - a review. J Clin Diagn Res 2017;11 (02):QE01-QE05

21 Ramanathan A, Eckardt MJ, Nelson BD, et al. Safety of a condom uterine balloon tamponade (ESM-UBT) device for uncontrolled primary postpartum hemorrhage among facilities in Kenya and Sierra Leone. BMC Pregnancy Childbirth 2018;18(01):168

22 Aderoba AK, Olagbuji BN, Akintan AL, Oyeneyin OL, Owa OO, Osaikhuwuomwan JA. Condom-catheter tamponade for the treatment of postpartum haemorrhage and factors associated with 
success: a prospective observational study. BJOG 2017;124(11): 1764-1771

23 Darwish AM, Abdallah MM, Shaaban OM, Ali MK, Khalaf M, Sabra AMA. Bakri balloon versus condom-loaded Foley's catheter for treatment of atonic postpartum hemorrhage secondary to vaginal delivery: a randomized controlled trial. J Matern Fetal Neonatal Med 2018;31(06):747-753

24 Revert M, Cottenet J, Raynal P, Cibot E, Quantin C, Rozenberg P. Intrauterine balloon tamponade for management of severe postpartum haemorrhage in a perinatal network: a prospective cohort study. BJOG 2017;124(08):1255-1262

25 Kaya B, Tuten A, Daglar K, et al. Balloon tamponade for the management of postpartum uterine hemorrhage. J Perinat Med 2014;42(06):745-753

26 Natarajan A, Alaska Pendleton A, Nelson BD, et al. Provider experiences with improvised uterine balloon tamponade for the management of uncontrolled postpartum hemorrhage in Kenya. Int J Gynaecol Obstet 2016;135(02):210-213

27 Burke TF, Ahn R, Nelson BD, et al. A postpartum haemorrhage package with condom uterine balloon tamponade: a prospective multi-centre case series in Kenya, Sierra Leone, Senegal, and Nepal. BJOG 2016;123(09):1532-1540

28 Pendleton AA, Natarajan A, Ahn R, Nelson BD, Eckardt MJ, Burke TF. A qualitative assessment of the impact of a uterine balloon tamponade package on decisions regarding the role of emergency hysterectomy in women with uncontrolled postpartum haemorrhage in Kenya and Senegal. BMJ Open 2016;6(01):e010083

29 Burke TF, Danso-Bamfo S, Guha M, Oguttu M, Tarimo V, Nelson BD. Shock progression and survival after use of a condom uterine balloon tamponade package in women with uncontrolled postpartum hemorrhage. Int J Gynaecol Obstet 2017;139(01):34-38

30 Edwards A, Ellwood DA. Ultrasonographic evaluation of the postpartum uterus. Ultrasound Obstet Gynecol 2000;16(07):640-643

31 Mulic-Lutvica A, Bekuretsion M, Bakos O, Axelsson O. Ultrasonic evaluation of the uterus and uterine cavity after normal, vaginal delivery. Ultrasound Obstet Gynecol 2001;18(05): 491-498

32 Goldstuck N. Assessment of uterine cavity size and shape: a systematic review addressing relevance to intrauterine procedures and events. Afr J Reprod Health 2012;16(03):130-139

33 Barnhart KT, Izquierdo A, Pretorius ES, Shera DM, Shabbout M, Shaunik A. Baseline dimensions of the human vagina. Hum Reprod 2006;21(06):1618-1622

34 Tobechukwu MT, Ose-Emenim IB, Ehinwenma O. Sonographic evaluation of uterine cervical dimension within 4-24 weeks of pregnancy. Niger J Clin Pract 2011;14(04):400-404

35 Kassebaum NJ, Barber RM, Bhutta ZA, et al; GBD 2015 Maternal Mortality Collaborators. Global, regional, and national levels of maternal mortality, 1990-2015: a systematic analysis for the Global Burden of Disease Study 2015. Lancet 2016;388 (10053):1775-1812

36 Souza JP, Gülmezoglu AM, Vogel J, et al. Moving beyond essential interventions for reduction of maternal mortality (the WHO Multicountry Survey on Maternal and Newborn Health): a cross-sectional study. Lancet 2013;381(9879):1747-1755

37 Bowen LW, Beeson JH. Use of a large Foley catheter balloon to control postpartum hemorrhage resulting from a low placental implantation. A report of two cases. J Reprod Med 1985;30(08): 623-625

38 Tindell K, Garfinkel R, Abu-Haydar E, et al. Uterine balloon tamponade for the treatment of postpartum haemorrhage in resource-poor settings: a systematic review. BJOG 2013;120 (01):5-14

39 Kong CW, To WWK. Intraluminal pressure of uterine balloon tamponade in the management of severe post-partum hemorrhage. J Obstet Gynaecol Res 2018;44(05):914-921

40 Belfort MA, Dildy GA, Garrido J, White GL. Intraluminal pressure in a uterine tamponade balloon is curvilinearly related to the volume of fluid infused. Am J Perinatol 2011;28(08): 659-666 